\title{
Editorial
}

\section{Foreword to 4th International Conference on Whole-body Vibration Injuries Held at Hilton Montreal Bonaventure Hotel, Montreal, Canada 2-4 June 2009}

This multi-disciplinary conference was organized jointly by the Institut de recherche Robert-Sauvé en santé et en sécurité du travail (IRSST) and Concave Research Centre, Concordia University in Montreal in June 2009. Dr. Paul-Émile Boileau (IRSST) and Dr. Subhash Rakheja (Concordia University) co-chaired the Conference.

The 4th International Conference on Whole-Body Vibration Injuries was the first ever to be held in North America, succeeding to the first edition which was held in Southampton, U.K. in 1997, the second in Siena, Italy in 2000 and the third in Nancy, France in 2005. The program of the Conference was structured into 10 sessions and addressed such issues as epidemiology and the effects of whole-body vibration, biodynamics and modeling, exposure assessment, guidance and regulations and seating dynamics. The Conference was successful in bringing together researchers, practitioners, worker and employer representatives, and regulators from various parts of the world to share their experience, knowledge and specific needs in the very specialized area of whole-body vibration injuries.

The conference program included a total of 71 papers, of which 52 were given as oral and 19 as poster presentations. Of those papers that were submitted for publication and have undergone a rigorous peer review process, a total of 20 papers are published in this Special issue of the Industrial Health journal. These present some of the most recent research findings and trends with regard to epidemiology, modeling and seated body biodynamic responses and effects under single and multi-axis vibration, back support and postural effects on whole-body vibration exposure, discomfort and spinal fatigue assessments, frequency-weighting estimations and effects under horizontal vibration, and measurements and exposure assessments. On the other hand, these works put in evidence a gap of knowledge and consideration of the possible mechanisms involved in whole-body vibration injuries, thus suggesting that more attention should be given to this issue in the future.

On behalf of the authors, the guest editors would like to express their sincere appreciation to the substantial contributions of the many anonymous reviewers who committed their time and effort in making this Special issue possible. Most of all, the guest editors would like to express their thanks to Ms. Rie Sotoyama for her immense efforts in organizing and coordinating the review process, which was instrumental in providing the feedback to the authors and concluding this issue in a timely manner.

Editors of Special Issue

Paul-Émile BOILEAU, PhD

Scientific Director, IRSST, Montreal, Qc Canada

E-mail: boileau.paul-emile@irsst.qc.ca

Subhash RAKHEJA, PhD, FASME

CONCAVE Research Centre, Concordia University, Montreal, Qc Canada

E-mail: rakheja@alcor.concordia.ca

Setsuo MAEDA, Dr Eng, Dr Med Sci

Faculty of Applied Sociology, Kinki University, Higashiosaka City, Japan

E-mail:maeda@socio.kindai.ac.jp

Helmut SEIDEL, Dr Sci Med

Federal Institute of Occupational Safety and Health, Berlin, Germany

E-mail: seidel-helmut@t-online.de 